\title{
Original Clinical Article \\ COEXISTING DEPRESSIVE SYMPTOMS DO NOT LIMIT THE BENEFITS OF \\ CHRONIC NEUROMODULATION: A STUDY OF OVER 200 PATIENTS ${ }^{1}$
}

Kim A. Killinger 0000-0001-9228-8758 0000-0001-9228-8758 ${ }^{1,2}$, Jonathan Fergus ${ }^{2}$, Luke

Edwards $^{1}$, Judith A. Boura ${ }^{1,2}$, Jamie Bartley ${ }^{1,2}$, Priyanka Gupta ${ }^{3}$, Janice Tomakowsky ${ }^{1}$,

Jason Gilleran $^{1,2}$, Kenneth M. Peters ${ }^{1,2}$

${ }^{1}$ Beaumont Health, Royal Oak, MI

${ }^{2}$ Oakland University William Beaumont School of Medicine, Rochester, MI

${ }^{3}$ University of Michigan, Department of Urology, Ann Arbor, MI

Corresponding Author:

Kim A. Killinger

Beaumont, Royal Oak

3535 West 13 Mile Road Ste. 438

Royal Oak, MI 48073

Phone: 248.551.9295

Email: Kim.Killinger@beaumont.org

\footnotetext{
${ }^{1}$ This is the author manuscript accepted for publication and has undergone full peer review but has not been through the copyediting, typesetting, pagination and proofreading process, which may lead to differences between this version and the Version of Record. Please cite this article as doi:10.1002/nau.23356
} 
Abstract word count: 249

Manuscript word count: 2,423

Keywords: Urinary Bladder, Overactive; Implantable Neurostimulators; Depressive Symptoms

Disclosures: A single co-author reports personal fees from Medtronic, outside the submitted work. The primary author and all other co-authors have nothing to disclose.

\section{Acknowledgement}

Funding: Philanthropy-Ministrelli Program for Urology Research and Education (MPURE)

Kim A. Killinger ${ }^{1,2}$, Jonathan Fergus ${ }^{2}$, Luke Edwards ${ }^{1}$, Judith A. Boura ${ }^{1,2}$, Jamie Bartley ${ }^{1,2}$, Priyanka Gupta ${ }^{3}$, Janice Tomakowsky ${ }^{1}$, Jason Gilleran ${ }^{1,2}$, Kenneth M. Peters ${ }^{1,2}$ ${ }^{1}$ Beaumont Health, Royal Oak, MI

${ }^{2}$ Oakland University William Beaumont School of Medicine, Rochester, MI

${ }^{3}$ University of Michigan, Department of Urology, Ann Arbor, MI

Corresponding Author: Kim A. Killinger, Beaumont, Royal Oak, 3535 West 13 Mile Road Ste. 438, Royal Oak, MI 48073, Phone: 248.551.9295, Email: Kim.Killinger@beaumont.org

Abstract word count: 249

Manuscript word count: 2,423

Keywords: Urinary Bladder, Overactive; Implantable Neurostimulators; Depressive Symptoms

Disclosures: A single co-author reports personal fees from Medtronic, outside the submitted work. The primary author and all other co-authors have nothing to disclose.

\section{Acknowledgement}

Funding: Philanthropy-Ministrelli Program for Urology Research and Education (MPURE)

This article is protected by copyright. All rights reserved. 
Kim A. Killinger ${ }^{1,2}$, Jonathan Fergus ${ }^{2}$, Luke Edwards ${ }^{1}$, Judith A. Boura ${ }^{1,2}$, Jamie

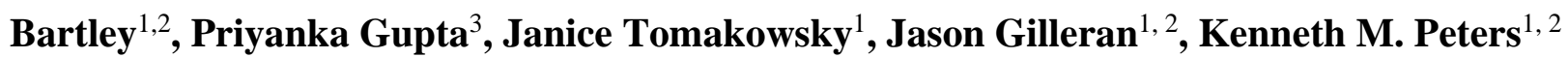

${ }^{1}$ Beaumont Health, Royal Oak, MI

${ }^{2}$ Oakland University William Beaumont School of Medicine, Rochester, MI

${ }^{3}$ University of Michigan, Department of Urology, Ann Arbor, MI

Corresponding Author:

Kim A. Killinger

Beaumont, Royal Oak

3535 West 13 Mile Road Ste. 438

Royal Oak, MI 48073

Phone: 248.551.9295

Email: Kim.Killinger@beaumont.org

Abstract word count: 249

Manuscript word count: 2,423

Keywords: Urinary Bladder, Overactive; Implantable Neurostimulators; Depressive Symptoms

Disclosures: A single co-author reports personal fees from Medtronic, outside the submitted work. The primary author and all other co-authors have nothing to disclose. 


\section{Acknowledgement}

Funding: Philanthropy-Ministrelli Program for Urology Research and Education (MPURE)

Kim A. Killinger ${ }^{1,2}$, Jonathan Fergus ${ }^{2}$, Luke Edwards ${ }^{1}$, Judith A. Boura ${ }^{1,2}$, Jamie

Bartley $^{1,2}$, Priyanka Gupta ${ }^{3}$, Janice Tomakowsky $^{1}$, Jason Gilleran ${ }^{1,2}$, Kenneth M. Peters ${ }^{1,2}$

${ }^{1}$ Beaumont Health, Royal Oak, MI

${ }^{2}$ Oakland University William Beaumont School of Medicine, Rochester, MI

${ }^{3}$ University of Michigan, Department of Urology, Ann Arbor, MI

Corresponding Author:

Kim A. Killinger

Beaumont, Royal Oak

3535 West 13 Mile Road Ste. 438

Royal Oak, MI 48073

Phone: 248.551.9295

Email: Kim.Killinger@beaumont.org

Abstract word count: 249

Manuscript word count: 2,423

Keywords: Urinary Bladder, Overactive; Implantable Neurostimulators; Depressive Symptoms 
Disclosures: A single co-author reports personal fees from Medtronic, outside the submitted work. The primary author and all other co-authors have nothing to disclose.

\section{Acknowledgement}

Funding: Philanthropy-Ministrelli Program for Urology Research and Education (MPURE)

\section{ABSTRACT}

Aims: To examine the relationship between coexisting depressive symptoms and outcomes after staged neuromodulation procedures for refractory urological symptoms.

Methods: Adults who enrolled in a prospective database and completed a Personal Health Questionnaire Depression Scale (PHQ-8) at baseline were reviewed. The PHQ-8 and Generalized Anxiety Disorder (GAD-7) assessed depressive/anxiety symptoms pre and 6 months post device implant. Urological symptoms were assessed with The Interstitial Cystitis Symptom Index/Problem Index (ICSI-PI) and Overactive Bladder Questionnaire (OAB-q) at baseline, 3 and 6 months, and Global Response Assessments (GRA) post implant. Subjects, grouped by PHQ $<10$ and PHQ $\geq 10$, were compared with Pearson's Chi-square, Fisher's Exact or Wilcoxon rank test, and Spearman's correlations.

Results: In 117 PHQ $<10$ and 84 PHQ $\geq 10$ patients, age differed (mean 59 vs. 52 years; $\mathrm{p}=0.001)$, and PHQ $<10$ had lower GAD-7, ICSI-PI and OAB-q scores at baseline ( $<<0.0001$, $\mathrm{p}=0.0003$ and $\mathrm{p}<0.0008$ respectively). Implantation rates were similar between groups. Reoperation and complication rates within the first 6 months did not differ, similar proportions (majority) were improved on the GRA at each time point, and ICSI-PI and OAB-q scores improved significantly. PHQ scores only improved significantly for those with baseline PHQ 
$\geq 10$. Baseline PHQ strongly correlated with GAD-7 at baseline and 6 months, and baseline ICSI-

PI. Change in PHQ positively correlated with the change in GAD-7, 6 month ICSI-PI, and change in ICSI-PI from baseline to 6 months.

Conclusions: Coexisting depressive symptoms do not limit the efficacy of neuromodulation and PHQ improvements correlate with improved anxiety and bladder symptoms.

\section{INTRODUCTION}

Urinary symptoms can disrupt social, physical, occupational, sexual, and recreational activities and as a result, have significant negative impact on the psychological and social well-being of the affected individual. Sacral neuromodulation (InterStim ${ }^{\circledR} ;$ Medtronic Inc, Minneapolis, MN) is a well-established therapeutic option for patients with refractory overactive bladder $(\mathrm{OAB})$ who have failed behavioral modification, pelvic floor rehabilitation, and anticholinergic therapy. ${ }^{1}$ Although sacral neuromodulation is FDA approved for bladder and bowel symptoms, improvements can also be achieved by directly stimulating the pudendal nerves to increase afferent stimulation. ${ }^{2}$ Neuromodulation is a minimally invasive, reversible treatment that has a high rate of success and a low incidence of serious adverse events. ${ }^{3}$ It has been shown that successful therapies for urinary incontinence including neuromodulation improve quality of life. ${ }^{4}$

Thus, over the last decade, neuromodulation has become an attractive treatment option for patients with refractory urinary urgency, frequency, and urge incontinence. Although many groups have aimed to determine predictors of response to therapy, little is known about how coexisting depressive symptoms affect initial response to, or outcomes of, neuromodulation. Siegel et al. showed that neuromodulation for voiding symptoms can positively affect depression scores. ${ }^{4}$ On the other hand, Van Balken's group found that 
patients' with poor mental health were prone to failing neuromodulation with percutaneous tibial nerve stimulation (PTNS). ${ }^{5} \mathrm{~A}$ review of the literature found that although coexisting depression and other affective disorders negatively impact response to medical therapy in a variety of disease processes, ${ }^{6}$ few have examined how depressive symptoms at baseline might affect response to chronic neuromodulation for bladder symptoms. Therefore, we explored the impact of coexisting depressive symptoms assessed by validated questionnaires on outcomes in over 200 patients undergoing neuromodulation for refractory urological symptoms.

\section{MATERIALS AND METHODS}

After receiving Institutional Review Board approval in 2004, all patients over 18 years of age that were scheduled for a staged InterStim ${ }^{\circledR}$ procedure at our large referral center were invited to enroll in a prospective, longitudinal, observational neuromodulation database study. Participants choosing to enroll (approximately 82 to $95 \%$ of eligible patients) completed questionnaires by mail at baseline (pre-treatment) and during follow-up until device explantation or voluntary withdrawal from the study. Telephone calls, and repeated mailings were conducted as needed in an attempt to obtain complete follow up data. Medical history and surgical data, and complications, reoperations, and reprogramming sessions after implant were obtained from reviewing participants' medical records. In 2013, measures to evaluate depressive and anxiety symptoms at baseline and 6 months were added to the prospective study. This analysis represents a retrospective review of the patients enrolled in the database that completed the depression and anxiety measures prior to neuromodulation. 
Some patients had office percutaneous nerve evaluation (PNE) to determine initial response to treatment, but the majority had a two-stage operative procedure, which has been previously described. Briefly, during the first procedure (Stage I), a tined quadripolar lead was implanted at either the sacral or, alternatively, the pudendal nerve and connected to an external programmable device. After testing the device for approximately two weeks as an outpatient, patients returned for a second procedure (Stage II). If voiding symptoms had improved by at least $50 \%$ on voiding diaries, an implantable pulse generator (IPG) was placed. If symptoms did not improve by this margin, then the lead was removed and the patient did not proceed to permanent implant.

Outcomes during the first 6 months after implant were evaluated. Depressive symptoms and anxiety were assessed at baseline and 6 months post-implant with the Personal Health Questionnaire Depression Scale (PHQ-8) and the Generalized Anxiety Disorder (GAD-7) questionnaire. The PHQ-8 questionnaire is an 8-item validated depression scale that has been used as a screening tool in population based studies. ${ }^{7}$ PHQ scores are categorized as 5-9 (mild depressive symptoms), 10-14 (moderate), 15-19 (moderately severe), and $\geq 20$ (severe depressive symptoms). The GAD-7 questionnaire is a 7-item validated scale to assess generalized anxiety disorder. ${ }^{8}$ Scores range from 0-21 with higher scores indicating a higher degree of anxiety and $\geq 10$ has been identified as a reasonable cutoff for identifying anxiety ${ }^{8}$.

When the prospective data collection study began in 2004, many of our patients were undergoing neuromodulation for urinary urgency, frequency, and nocturia associated with IC/BPS, so urinary symptoms were measured in all patients with the validated Interstitial Cystitis Symptom Index and Problem Index (ICSI-PI; composite scores range from 0-36 with higher scores indicating more severity/bother) pre-treatment, and at 3 and 6 months post IPG implant. In 
2009, the Overactive Bladder Questionnaire Short Form (OAB-q SF; validated in patients with $\mathrm{OAB})$ was added to assess symptom severity (OAB-q ss) and health related quality of life (OABq HRQOL). Overall improvement in symptoms was assessed with scaled Global Response Assessments (GRA) between Stage I and Stage II, as well as at 3 and 6 months post IPG implant. On the GRA, patients rated overall changes in symptoms on a 7-point scale as "markedly worse, moderately worse, mildly worse, same, slightly improved, moderately improved, or markedly improved." Treatment responders were those that reported a moderate or marked improvement on the GRA.

Subjects were grouped by baseline PHQ score $<10$ and $\geq 10$ (suggesting major depressive symptoms) and compared using Pearson's Chi-square, Fisher's Exact or Wilcoxon rank test, and Spearman's correlations at each separate time point. Within and between groups paired changes in patients that completed questionnaires at both baseline and 6 months were examined with Sign tests. A p-value of $<0.05$ was considered statistically significant. All analyses used the SAS ${ }^{\circledR}$ System for Windows ${ }^{\circledR}$ (version 9.3, SAS Institute, Inc., Cary, NC).

\section{RESULTS}

Most patients in this longitudinal database study had enrolled prior to adding the PHQ-8 questionnaire. Therefore, of 937 patients in the database, only 201 (21.5\%) with complete baseline PHQ-8 questionnaire data were selected for inclusion. Of those included, most were female $(173 / 201 ; 86.1 \%)$, Caucasian $(87.6 \%)$, mean age was $56.0 \pm 16.3$ years, and mean body mass index (BMI) was $28.7 \pm 7.1$. Primary indications for neuromodulation varied and reflected our clinical population: overactive bladder ( $\mathrm{n}=91 ; 67$ wet, 24 dry), pelvic pain without an interstitial cystitis/bladder pain syndrome (IC/BPS) diagnosis $(n=42)$, idiopathic urinary 
retention $(n=30)$, voiding and pelvic pain symptoms related to IC/BPS $(n=28)$, fecal incontinence $(n=3)$, and neurological condition $(n=7)$. On the PHQ-8 at baseline, 84 subjects had symptoms of major depression (PHQ scores $\geq 10$ ) and of these 84 subjects, 19 subjects had scores suggestive of severe major depression (score $\geq 20$ ).

When patients with PHQ $<10$ were compared to those with PHQ score $\geq 10$, mean age was significantly different ( $59 \pm 17$ vs. $52 \pm 15$ years; $p=0.001)$ but other demographics, initial success leading to IPG implantation, and operative characteristics did not differ between groups (Table 1). Since depressive and anxiety symptoms often coexist, it is not surprising that those with lower PHQ $(<10)$ also had significantly lower scores on the GAD-7 at baseline (median 4 vs. 13; $\mathrm{p}<0.0001)$ and 6 months (median 1 vs. 8; $\mathrm{p}<0.0001)$ (Table 2). For those subjects that had both baseline and 6 month data, GAD-7 scores only improved significantly in the PHQ $<10$ group ( $n=49 ; p=0.01)$ and on the PHQ, only those in the PHQ $\geq 10$ group had statistically significant improvement $(n=30 ; p=0.013)$ (Table 2). Interestingly, the overall mean PHQ score in the PHQ $\geq 10$ group improved enough to move from the "moderately severe depressive symptoms" into the "moderate" category.

Table 3 illustrates changes in urological symptoms after neuromodulation. At baseline, the PHQ $<10$ group had statistically significantly lower composite ICSI-PI $(p=0.0003)$ and OAB-q ss scores $(p=0.0008)$ compared to PHQ $\geq 10$. In patients with data for both baseline and 6 months measures, ICSI-PI and OAB-q ss scores improved over time $(\mathrm{p}<0.0001$ for both groups). Similarly, the PHQ <10 group had significantly better OAB-q HRQOL scores at baseline $(\mathrm{p}<0.0001)$ and both PHQ groups improved over time $(\mathrm{p}=0.005$ and $\mathrm{p}<0.0001$ respectively). On the GRA, similar proportions ( $\geq 50 \%$ at each time point) in both groups had improved at 2 weeks after lead placement, and at 3 and 6 months. We used Spearman 
correlations to examine baseline PHQ-8 scores, and the change in PHQ score between baseline and 6 months, to determine correlations with GAD-7 and ICSI-PI scores. The total PHQ-8 at baseline was strongly correlated with the baseline GAD-7 $(r=0.74 ; p<0.0001)$, the 6 month GAD-7 score $(r=0.62 ; \mathrm{p}<0.0001)$ and the baseline total ICSI-PI score $(r=0.29 ; \mathrm{p}<0.0001)$ but not correlated with the change in GAD-7, the 6 month total ICSI-PI score or the change in total ICSI-PI score. The change in total PHQ-8 score (between baseline and 6 months) was somewhat negatively correlated with the baseline total GAD-7 $(r=-0.34 ; \mathrm{p}=0.0017)$, but correlated positively with the change in GAD-7 score $(r=0.55 ; \mathrm{p}<0.0001)$, the ICSI-PI score at 6 months $(\mathrm{r}=0.33 ; \mathrm{p}=0.0025)$ and the change in ICSI-PI score $(\mathrm{r}=0.33 ; \mathrm{p}=0.0027)$. These correlations provide further evidence of association between depressive and anxiety symptoms, and their impact on problematic bladder symptoms.

Although the primary focus of the study was to examine the impact of depressive symptoms on neuromodulation outcomes, we also compared patients grouped by GAD score $<10$ and $\geq 10$ (Table 4). Similar to the analysis of patients grouped by PHQ-8 scores, IPG implantation rate did not differ, but significantly fewer complications were seen in those with lower anxiety scores $(\mathrm{GAD}<10)(\mathrm{p}=0.018)$. Not surprisingly, the GAD $<10$ group had lower baseline PHQ-8 (p<0.0001), ICSI-PI ( $\mathrm{p}=0.0004)$ and OAB-q SS (p=0.004) scores, and higher OAB-q HRQOL scores ( $p<0.0001)$. Although PHQ scores only decreased significantly in the GAD $\geq 10$ group $(p=0.036)$, both groups demonstrated significant improvements over time on the ICSI-PI, OAB-q SS and OAB-q HRQOL measures.

\section{Discussion}


Concomitant affective disorders, particularly depression, have been shown to affect outcomes, complications, and response to treatment. ${ }^{6,9,10}$ Yet, little is known about the impact on neuromodulation outcomes even though depressive symptoms are associated with bladder symptoms. ${ }^{11}$ Burg et al. dichotomized patients undergoing coronary artery bypass grafting based on preoperative depression scores and found that depression was a significant predictor of hospitalization, ongoing pain, and failure to return to previous activity levels, all at 6 months post operatively. ${ }^{10}$ In a study of psychosocial factors related to neuromodulation use, Levin et al. demonstrated significant improvements in depression after treatment but did not evaluate whether baseline depression predicted overall outcomes. ${ }^{12}$ Another group found that patients with poor mental health were more prone to failing neuromodulation treatment for overactive bladder with percutaneous tibial nerve stimulation (PTNS). ${ }^{5}$ More recently, 86 men and women with $\mathrm{OAB}$ or non-obstructive urinary retention were retrospectively studied to explore the impact of anxiety and depression on neuromodulation response. ${ }^{13}$ Conducted in Europe, the study examined the relationship between baseline depressive/anxiety symptoms assessed with the Hospital Anxiety and Depression Scale, voiding diaries and urodynamics, and neuromodulation response initially and at 1 year. ${ }^{13}$ Similar to the results reported here, there was no significant relationship between abnormal depressive/anxiety symptom scores and failure to respond to neuromodulation. However, the study did not evaluate changes in depressive/anxiety or urological symptom outcomes over time.

We sought to examine whether depressive symptoms as measured by PHQ-8 would portend any change in symptom response, outcomes, or complications over the short term after neuromodulation therapy. This study did not demonstrate an inferior response to neuromodulation among patients exhibiting major depressive symptoms (PHQ- 8 scores $\geq 10$ ). It 
is worth noting that at baseline, those with PHQ- 8 scores $\geq 10$ had significantly higher ICSI-PI and $\mathrm{OAB}-\mathrm{q}$ ss scores suggesting a higher level of initial urinary bother. This is not surprising since $\mathrm{OAB}$ has been associated with affective symptoms, ${ }^{11}$ and $\mathrm{OAB}$ patients with depression report more severe urinary incontinence symptoms, greater bother and more impact on quality of life. ${ }^{14}$ Measuring the impact of neuromodulation on depressive symptoms was not the aim of this study, but depressive symptoms did decrease significantly over 6 months after neuromodulation in those with PHQ-8 scores $\geq 10$ at baseline. Although interesting, this finding may be due to the fact that significant decreases in scores are likely more probable in those that have more room for improvement (higher baseline scores). Also, the similar outcomes in patients when examine categorized by PHQ and GAD scores separately highlights the known association between depressive and anxiety symptoms. Even though patients undergoing neuromodulation for OAB may have coexisting depression and/or anxiety, and poor mental health has been shown to negatively influence response to neuromodulation with $\mathrm{PTNS}^{5}$, our results suggest that preexisting or concomitant depressive symptoms may not limit the therapeutic benefits of neuromodulation with an implanted device.

In addition to symptom improvements, complications, reoperations, and device explantations are also outcomes important to both clinicians and patients. Overall, lower reoperation and complication rates were found in this study compared to some other published results. ${ }^{3}$ These findings may be attributable to differences in length of follow-up or definitions of reoperations or complications. Even though our data did not suggest that patients with depressive symptoms have higher complication or reoperation rates, we only evaluated these outcomes over 6 months and longer follow-up may reveal differences between groups. Notwithstanding, 
achieving symptom improvements to justify device implant and improve quality of life while avoiding complications or reoperation, are key goals for both patients and clinicians.

Strengths of our study include sample size, use of validated questionnaires, and the prospective collection of pre and post implant data, which also enabled the study of changes in affective and urinary symptoms over time. Limitations include a potential for selection bias since not all patients undergoing neuromodulation elected to enroll in our prospective data collection study. Additionally, not all patients returned questionnaires at every time point and it is possible that not all complications were captured if treated outside our institution. The questionnaires used in this study captured changes in symptoms for the most common neuromodulation indications at our center, however future studies might examine other less common indications with condition specific validated measures. Our study sample was predominantly women and patients presented with a variety of voiding/storage symptoms, which is representative of our clinical population undergoing neuromodulation. Even though the site of lead placement (pudendal or sacral) and indications for neuromodulation varied, it is unlikely that these differences influenced outcomes since these data did not differ significantly between groups.

\section{Conclusion}

This study suggests that coexisting depressive symptoms do not limit the efficacy or therapeutic benefits of neuromodulation for refractory bladder symptoms over the short term. As such, depressive symptoms should not preclude neuromodulation device placement in appropriately selected patients and it is reasonable to expect similar outcomes for these patients. Future studies might more fully explore changes in psychological symptoms after neuromodulation as well as outcomes over the long term. 


\section{Table Legends:}

Table 1

* within the first 6 months

OAB: Overactive Bladder

UUI: urinary urge incontinence

IPG: implantable pulse generator

PNE: percutaneous nerve evaluation

\section{Table 2}

GAD-7: Generalized Anxiety Disorder Questionnaire PHQ-8: Personal Health Questionnaire Depression Scale

*Only in patients with both baseline and 6 month data NT: Not tested

\section{Table 3}

*Only in patients with both baseline and 6 month data

ICSI-PI: Interstitial Cystitis Symptom and Problem Index

OAB-q: Overactive Bladder Questionnaire

HRQOL: Health related quality of life

\section{Table 4}

IPG: implantable pulse generator

*Only in patients with both baseline and 6 month data

PHQ-8: Personal Health Questionnaire Depression Scale

ICSI-PI: Interstitial Cystitis Symptom and Problem Index

OAB-q: Overactive Bladder Questionnaire 
HRQOL: Health related quality of life

\section{References}

1. Amend B, Khalil M, Kessler TM, Sievert KD. How does sacral modulation work best? Placement and programming techniques to maximize efficacy. Curr Urol Rep. 2011;12:327-335.

2. Peters KM, Killinger KA, Boguslawski BM, Boura JA. Chronic pudendal neuromodulation: expanding available treatment options for refractory urologic symptoms. Neurourol Urodynam. 2010, 29: 1267-71,

3. Siddiqui NY, Wu JM, Amundsen CL. Efficacy and adverse events of sacral nerve stimulation for overactive bladder: A systematic review. Neurourol Urodynam. 2010;29 Suppl 1:S18-23.

4. Siegel S, Noblett K, Mangel J, Griebling TL, Sutherland SE, Bird ET, et al. Three-year follow-up results of a prospective, multicenter study in overactive bladder subjects treated with sacral neuromodulation. Urology 2016, 94: 57-63.

5. van Balken MR, Vergunst H, Bemelmans BL. Prognostic factors for successful percutaneous tibial nerve stimulation. Eur Urol. 2006;49:360-365.

6. Rosenberger PH, Jokl P, Ickovics J. Psychosocial factors and surgical outcomes: An Evidence Based Literature review. J Am Acad Orthop Surg. 2006; 14: 397-405.

7. Kroenke K, Strine TW, Spitzer RL, Williams JB, Berry JT, Mohdad AH. The PHQ-8 as a measure of current depression in the general population. J Affect Disord. 2009; 114:16313. 
8. Spitzer RL, Kroenke K, Williams JB, Lowe B. A brief measure for assessing generalized anxiety disorder: the GAD-7. Arch Intern Med. 2006, 166:1092-7.

9. Tully PJ, Baker RA, Knight JL. Anxiety and depression as risk factors for mortality after coronary artery bypass surgery. J Psychosom Res. 2008, 64: 285-90.

10. Burg MM, Benedetto MC, Rosenberg R, Soufer R. Pre-surgical depression predicts medical morbidity 6 months after coronary artery bypass graft surgery. Psychosom Med. $2003 ; 65: 111-118$.

11. Vrijens D, Drossaerts J, van Koeveringe G, Van Kerrebroeck P, van Os J, Leue C. Affective symptoms and the overactive bladder - A systematic review. J Psychosom Res. 2015, 78: 295-108.

12. Levin PJ, Siddiqui NY, Wu JM, Amundsen CL. Psychosocial factors related to the use of InterStim for the treatment of refractory overactive bladder. Fem Pelvic Med Reconstruc Surg. 2014, 20: 272-275.

13. Drossaerts J, Vrijens D, Leue C, Schilders I, Van Kerrebroeck P, van Koeveringe G. Screening for depression and anxiety in patients with storage or voiding dysfunction: a retrospective cohort study predicting outcome of sacral neuromodulation. Neurourol Urodynam. 2016, 35:1011-1016.

14. Lai 0000-0003-2691-994X 0000-0003-2691-994X HH, Shen B, Rawal A, Vetter J. The relationship between depression and overactive bladder/urinary incontinence symptoms in the clinical OAB population. BMC Urol. 2016, 16: 60.

Table 1. Descriptive Statistics

\begin{tabular}{lccc}
\hline & $\begin{array}{c}\text { PHQ }<10 \\
\mathrm{~N}=117\end{array}$ & $\begin{array}{c}\text { PHQ } \geq 10 \\
\mathrm{~N}=84\end{array}$ & P value \\
\hline Primary Indication & & & 0.59 \\
\hline
\end{tabular}

This article is protected by copyright. All rights reserved. 


\begin{tabular}{|c|c|c|c|}
\hline - $\quad$ Fecal Incontinence & $2(1.7 \%)$ & $1(1.2 \%)$ & \\
\hline - $\mathrm{IC} / \mathrm{PBS}$ & $16(13.7 \%)$ & $12(14.3 \%)$ & \\
\hline - Neurological Condition & $5(4.3 \%)$ & $2(2.4 \%)$ & \\
\hline - OAB dry & $15(12.8 \%)$ & $9(10.7 \%)$ & \\
\hline - $\quad$ OAB with UUI & $43(36.8 \%)$ & $24(28.6 \%)$ & \\
\hline - Pelvic Pain & $19(16.2 \%)$ & $23(27.4 \%)$ & \\
\hline - Retention & $17(14.5 \%)$ & $13(15.5 \%)$ & \\
\hline \multicolumn{4}{|l|}{ Stage 1 operative time (minutes) } \\
\hline Median (25th, 75th) & $45(35,59)$ & $43(33,54)$ & 0.40 \\
\hline Min to Max & 22 to 149 & 19 to 110 & \\
\hline \multicolumn{4}{|l|}{ Lead Location } \\
\hline - $\quad$ Pudendal Lead & $54(46.2 \%)$ & $38(45.2 \%)$ & 0.90 \\
\hline - Sacral Lead & $63(53.9 \%)$ & $46(54.8 \%)$ & \\
\hline Office PNE & $15 / 110(13.6 \%)$ & $6 / 82(7.3 \%)$ & 0.17 \\
\hline IPG implant & $96(82.1 \%)$ & $76(90.5 \%)$ & 0.09 \\
\hline After IPG implant: & $\mathrm{N}=96$ & $\mathrm{~N}=76$ & \\
\hline \multicolumn{4}{|l|}{ Number of Reprogrammings* } \\
\hline 0 & $77(80.2 \%)$ & $60(79.0 \%)$ & 0.58 \\
\hline 1 & $18(18.8 \%)$ & $13(17.1 \%)$ & \\
\hline 2 & 0 & $2(2.6 \%)$ & \\
\hline 3 & $1(1.0 \%)$ & $1(1.3 \%)$ & \\
\hline \multicolumn{4}{|l|}{ Number of Reoperations* } \\
\hline 0 & $87(90.6 \%)$ & $71(93.4 \%)$ & 0.51 \\
\hline 1 & $9(9.4 \%)$ & $5(6.6 \%)$ & \\
\hline Number of Complications* & $\mathrm{N}=95$ & & \\
\hline 0 & $86(90.5 \%)$ & $63(82.9 \%)$ & 0.27 \\
\hline 1 & $8(8.4 \%)$ & $12(15.8 \%)$ & \\
\hline 2 & $1(1.1 \%)$ & $1(1.3 \%)$ & \\
\hline
\end{tabular}

Table 2. GAD-7 and PHQ-8 Scores

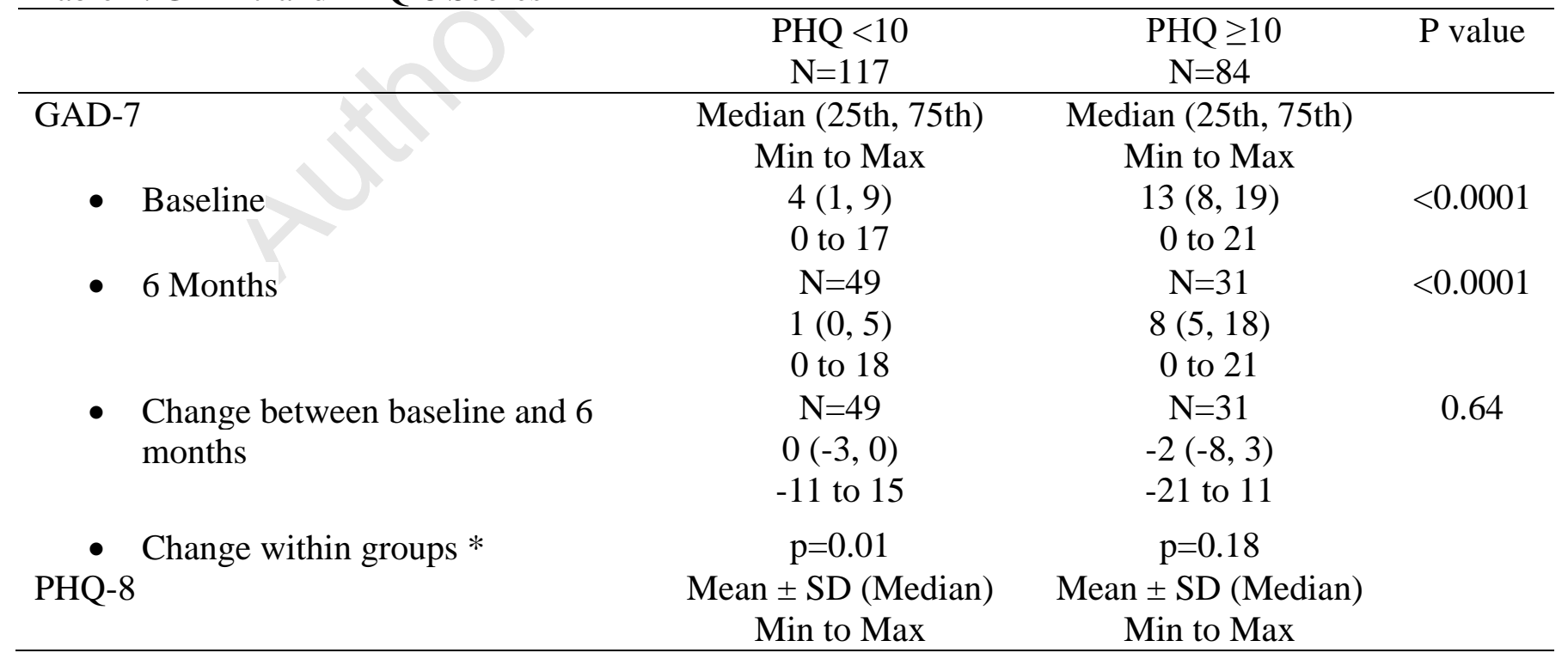

This article is protected by copyright. All rights reserved. 
- Baseline

- 6 Months

- Change between baseline and 6 months

$$
\begin{gathered}
4.3 \pm 3.1(4.0) \\
0 \text { to } 9 \\
\mathrm{~N}=50
\end{gathered}
$$$$
3.6 \pm 3.6(2.5)
$$$$
0 \text { to } 15
$$$$
\mathrm{N}=50
$$$$
-0.2 \pm 3.8(-0.5)
$$$$
-8 \text { to } 10
$$

$15.8 \pm 4.1(15)$

10 to 24

$\mathrm{N}=30$

$12.3 \pm 6.2(12)$

0 to 23

$\mathrm{N}=30$

$-3.3 \pm 6.4(-2.5)$

-20 to 9

$\mathrm{p}=0.013$

- Change within groups *

$\mathrm{p}=0.15$

NT

NT

NT

Table 3. Urological Symptom Measures

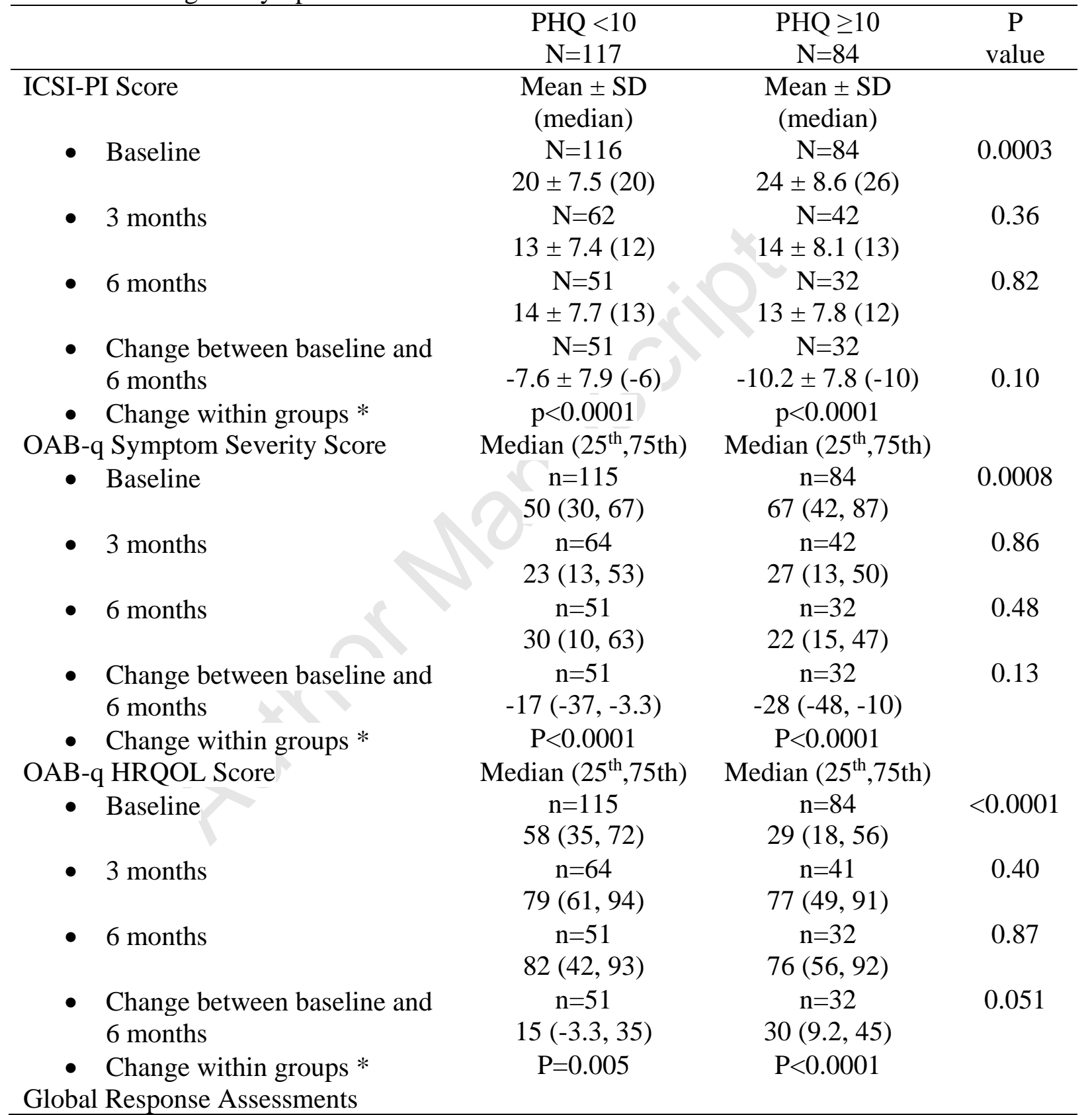

This article is protected by copyright. All rights reserved. 
(Moderately/Markedly Improved)

- Between Stages I and II

\begin{tabular}{lcc}
$55 / 81(67.9 \%)$ & $49 / 60(81.7 \%)$ & 0.066 \\
$36 / 64(56.3 \%)$ & $21 / 42(50 \%)$ & 0.53 \\
$28 / 51(54.9 \%)$ & $21 / 32(65.6 \%)$ & 0.33 \\
\hline
\end{tabular}

- 3 months

$28 / 51(54.9 \%)$

$21 / 32(65.6 \%)$

Table 4. Comparison of Patients Grouped by Baseline GAD score

This article is protected by copyright. All rights reserved. 
GAD $<10$

$\mathrm{GAD} \geq 10$

IPG implant

$98(82.4 \%)$

$\mathrm{N}=82$

$P$ value

After IPG implant:

Number of Reoperations

0

1

Number of Complications

0

1

2

PHQ-8

- Baseline

- 6 months

$\mathrm{n}=98$
$91(92.9 \%)$
$7(7.1 \%)$
$\mathrm{n}=98$
$91(92.9 \%)$
$7(7.1 \%)$
0

Median $\left(25^{\text {th }}, 75\right.$ th $)$

$\mathrm{n}=119$

$5(2,9)$

$74(90.2 \%)$

0.12

- 6 months

- $\quad$ Change between baseline and 6 months

$\mathrm{n}=50$

$3(1,6)$

$\mathrm{n}=50$

$-1(-2,1)$

$\mathrm{P}=0.08$

- $\quad$ Change within groups *

ICSI-PI Score

- Baseline

Mean \pm SD

(median)

$\mathrm{n}=118$

$19.5 \pm 8.0(19.5)$

$\mathrm{n}=63$

- 3 months

$13.0 \pm 7.6(11)$

$\mathrm{n}=50$

$\mathrm{n}=74$

0.58

$67(90.5 \%)$

$7(9.5 \%)$

$\mathrm{n}=73$

0.018

$58(79.5 \%)$

$13(17.8 \%)$

$2(2.7 \%)$

Median $\left(25^{\text {th }}, 75\right.$ th $)$

- 6 months

$12.9 \pm 8.2(12)$

$\mathrm{n}=50$

- Change between baseline and 6

$-7.3 \pm 7.1(-6)$

$\mathrm{P}<0.0001$

$$
\begin{gathered}
\mathrm{n}=82 \\
15(9,18)
\end{gathered}
$$

$<0.0001$

$$
\mathrm{n}=30
$$

$11.5(5,18)$

$$
\mathrm{n}=30
$$

$-2.5(-8,1)$

$\mathrm{P}=0.036$

Mean \pm SD

(median)

$$
\mathrm{n}=82
$$

0.0004

$23.5 \pm 8.0(25)$

$\mathrm{n}=41$

0.67

$13.7 \pm 7.8(12)$

$\mathrm{n}=33$

0.41

$14.2 \pm 6.9(13)$

$\mathrm{n}=33$

0.08

- Change within groups *

Global Response Assessments

(Moderately/Markedly Improved)

$\mathrm{n}(\%)$

$60 / 84(71.4 \%)$

$36 / 64(56.3 \%)$

$28 / 50(56.0 \%)$

- 6 months

OAB-q Symptom Severity Score

- Baseline

- 3 months

- 6 months

- $\quad$ Change between baseline and 6 months

- Change within groups *

OAB-q HRQOL Score

- Baseline

- 3 months

$$
\mathrm{n}=118
$$

$50(27,70)$

$$
\mathrm{n}=64
$$

$23(13,53)$

$$
\mathrm{n}=50
$$

$$
28(13,63)
$$

$$
\mathrm{n}=50
$$

$-19(-33,-3.3)$

$\mathrm{P}<0.0001$

$\mathrm{n}=118$

$58(32,74)$

$n=64$
Median $\left(25^{\text {th }}, 75\right.$ th $)$

Median $\left(25^{\text {th }}, 75\right.$ th $)$

$81(61,94)$

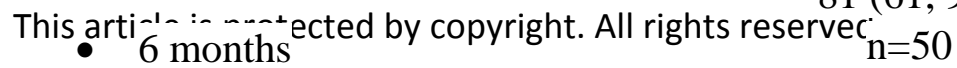

$82(42,95)$

- $\quad$ Change between baseline and 6

$$
\mathrm{n}=50
$$

$13(-3.1,34)$ months
$-10.5 \pm 8.7(-10)$

$\mathrm{P}<0.0001$

$$
\begin{array}{cc}
\mathrm{n}(\%) & \\
44 / 57(77.2 \%) & 0.45 \\
21 / 42(50.0 \%) & 0.53 \\
21 / 33(63.6 \%) & 0.49
\end{array}
$$

Median $\left(25^{\text {th }}, 75\right.$ th $)$

0.004

$63(43,83)$

$\mathrm{n}=42$

0.55

$25(13,47)$

$\mathrm{n}=33$

$23(17,50)$

$\mathrm{n}=33$

0.88

0.15

$-27(-50,-10)$

$\mathrm{P}<0.0001$

Median $\left(25^{\text {th }}, 75\right.$ th $)$

$\mathrm{n}=81$

$32(18,57)$

$\mathrm{n}=41$

$77(40,88)$

$\mathrm{n}=33$

$75(54,85)$

$\mathrm{n}=33$

$31(14,48)$
$<0.0001$

0.21

0.018 